\title{
1 AND 5 YEAR SURVIVAL ESTIMATES FOR PEOPLE WITH CIRRHOSIS OF THE LIVER IN ENGLAND, 1998-2009: A LARGE POPULATION STUDY
}

\author{
Sonia Ratib ${ }^{1}$, Kate M. Fleming ${ }^{1}$, Colin J. Crooks ${ }^{1}$, Guruprasad P. Aithal ${ }^{2}$, Joe \\ West $^{1}$ \\ ${ }^{1}$ Division of Epidemiology \& Public Health, University of Nottingham, UK \\ ${ }^{2} \mathrm{NIHR}$ Biomedical Research Unit in Gastrointestinal and Liver Diseases, Nottingham \\ University Hospitals NHS Trust and University of Nottingham, Nottingham, UK
}

\begin{abstract}
Abbreviations: GPRD-General Practise Research Database; HES-Hospital Episode Statistics; ONS-Office of National Statistics; ICD10-International Classification of Disease $10^{\text {th }}$ version, OPCS4-Office of Population Censuses and Surveys' classification of interventions and procedures $4^{\text {th }}$ version; UTS-Up to Standard.
\end{abstract}

Word count: 5556

Three tables and one figure

Conflict of interest: None

Financial support: University of Nottingham/National University Hospitals NHS Trust/National Institute for Health Research Senior Clinical Research Fellowship

\section{Correspondence:}

Sonia Ratib

Division of Epidemiology and Public Health

University of Nottingham

Nottingham NG5 1PB, UK

Tel: +44 (0)1158231344

Fax: +44 (0)115 8231946

e-mail: sonia.ratib@nottingham.ac.uk 


\section{ABSTRACT}

Background \& Aims: Large, population-based studies that have included the full spectrum of cirrhosis estimating survival taking into account time-at-risk are lacking. We aimed to report 1- and 5-year average survival rates for people with cirrhosis to be used in a clinical and health care policy setting.

Methods: We used the General Practice Research Database and linked English Hospital Episode Statistics to identify adult cases of cirrhosis from January 1998 to December 2009. We estimated 1- and 5-year survival according to whether time-atrisk was entirely ambulatory or followed an emergency hospital admission related to liver disease, stratified by age, sex and aetiology to be used in a clinical setting. We used a multivariate Cox-proportional hazards model with emergency hospital admission as a time-varying variable adjusted for Baveno IV stage of cirrhosis at diagnosis.

Results: We identified 5118 incident cases. Average survival probabilities at 1- and 5-years were $0.88(95 \% \mathrm{Cl} 0.87-0.90)$ and $0.74(95 \% \mathrm{Cl} 0.72-0.77)$ for the ambulatory group and $0.56(95 \% \mathrm{Cl} \quad 0.54-0.58)$ and $0.30(95 \% \mathrm{Cl} \quad 0.29-0.32)$ following hospitalisation, respectively. A hospital admission at diagnosis or subsequently for liver disease substantially impaired prognosis independent of stage of cirrhosis $(\mathrm{HR}=4.11,95 \% \mathrm{Cl} 3.70,4.58)$.

Conclusions: Emergency hospitalisation for liver disease heralds a downturn in a patient's outlook independent of their stage of cirrhosis. Our results provide population-based clinically translatable estimates of prognosis for the purposes of health care delivery and planning and communication to patients. 
Word count: 238 . Key words: cirrhosis; survival; aetiology; population-based. 


\section{INTRODUCTION}

The prognosis of liver cirrhosis is only well described amongst non-representative groups of patients as previous studies were limited by geographical region [1-3], disease severity $[4,5]$ or to a specific aetiology such as viral hepatitis $B[6,7]$. These studies are therefore of limited use in a clinical setting where patients with a range of aetiologies often ask about their prognosis, and they might also be misleading if used to advise how healthcare services should be tailored appropriately.

One common limitation of previous large epidemiological studies was a restriction to either primary or secondary healthcare records $[8,9]$ preventing a truly non selective population-based approach. Consequently they have either not taken into account the large proportion of patients with cirrhosis who remain ambulatory with no hospitalisation, or alternatively the studies have failed to identify cirrhosis diagnosed during a fatal hospitalisation. Having an emergency hospital admission is not just associated with a deterioration in cirrhosis, but can be associated with and potentially the cause of a number of fatal complications such as pulmonary embolism [10]. No previous study has quantified the difference in survival between patients with cirrhosis who are managed without hospitalisations, and those who are managed following a hospitalisation. Without a comprehensive and heterogeneous population of people with cirrhosis that includes varying time-at-risk, it is impossible to quantify survival estimates which can be used in a clinical setting and describe the effect of hospitalisation for the full spectrum of disease. 
The recent linkage of the General Practice Research Database with the Hospital Episode Statistics database and data from the Office for National Statistics has provided us with a novel opportunity to construct a study cohort that is representative of the whole population of people with cirrhosis in England.

The aim of the study is to determine 1- and 5-year average survival of people with cirrhosis and the independent effect of hospitalisation while taking account of their age, sex, underlying aetiology and stage of disease. 


\section{METHODS}

\section{Primary care data}

The General Practice Research Database (GPRD) is a longitudinal electronic database consisting of anonymised primary care records of over 10 million patients in the UK. Data are coded using the Read code system. Participating practices are assigned an up to standard (UTS) date on completion of regular audits confirming data quality and completeness. The GPRD has previously been shown to be representative of the population of the UK [11].

\section{Secondary care data}

The Hospital Episodes Statistics (HES) database comprises statutory records of all admissions (excluding out-patients) conducted in NHS trust hospitals and independent treatment centres in England. For each period of time under the care of a consultant, a patient is assigned a primary diagnosis and up to 19 secondary diagnoses, coded using the ICD10 (International Classification of Diseases, tenth revision), and/or up to 24 recorded procedures coded using the OPCS4 (Office of Population, Censuses and Surveys' classification of interventions and procedures, fourth revision).

\section{Death registry data}

The Office for National Statistics (ONS) provides death registry data for GPRD practices that are linked to the HES database. Date of death from GPRD records was used where ONS date of death was unavailable. 


\section{Study population}

We had access to data from all 244 GPRD practices in England linked to HES between April 1997 and August 2010 and to the ONS between April 1998 and December 2010. We defined cirrhosis in primary care if a person had a record containing a Read code for cirrhosis, oesophageal varices and/or portal hypertension in the GPRD. The Read code lists were adapted and updated from our previous externally validated definition [12] (Appendix1). We developed codes lists for cirrhosis diagnosis in secondary case from ICD10 (K70.3, K71.7, K72.1, K74.4, K74.5, K74.6, K76.6, I85.0, 185.9, 186.4, 198.2) and OPCS4 (J06.1, J06.2, T46.1, T46.2, G10.4, G10.8, G10.9, G14.4, G17.4, G43.7).

\section{Observation period}

The observation period commenced on the latest of (i) one year after the patient's current registration date or (ii) the practice's UTS date. The one year cut-off was used to avoid including potential prevalent cases, adapted from Lewis et al.'s methodology [13]. The period terminated on the earliest of (i) date of death, (ii) date the patient left the practice, or (iii) the practice's last data collection date. We identified incident cases between $1^{\text {st }}$ January 1998 and $31^{\text {st }}$ December 2009. 


\section{Validating case definition}

For people with a cirrhosis diagnosis recorded in primary care we established how many had a hospital admission related to liver disease (e.g. alcoholic liver disease) (Appendix2). We identified whether the admissions were elective or emergency defined as per the NHS Information Centre definition [14].

For patients identified with cirrhosis from secondary care records only, we searched for evidence of liver disease in their healthcare records (Appendix3) and anywhere on their death certificate (Appendix4). We excluded patients who had a record of cancer and an isolated procedure relating to ascites and no other evidence or death related to liver disease. For the remaining patients we examined their primary care free text data for terms related to cirrhosis.

\section{Diagnosis date}

For each patient we assigned the date of diagnosis as the first date associated with a Read or ICD10/OPCS4 code for cirrhosis within the observation period. Patients younger than 18 years at diagnosis were excluded.

\section{Exposure of interest: Patient setting at diagnosis and in subsequent follow up.}

We categorised patients into three groups based on the patient setting:

(1) Ambulatory at first diagnosis. These were patients who had a first record of cirrhosis in primary care or an elective admission in secondary care records.

(2) Ambulatory with subsequent emergency hospital admission for liver disease: These were group (1) patients who had a subsequent emergency hospital admission related to liver disease. 
(3) Hospitalised at first diagnosis: These were patients whose first record of cirrhosis occurred during an emergency hospital admission.

\section{Aetiology}

We searched the patient's medical records for evidence of viral hepatitis, autoimmune and metabolic diseases. We defined patients as having an underlying alcoholic aetiology if there was mention in their records of alcoholism for example alcohol abuse, addiction or dependence, 'problem drinking' or referral to alcohol cessation services, or if their weekly alcohol consumption in their primary care records exceeded the Chief Medical Officer's recommended amount (14 units for women, 21 units for men) [15]. Our Read code list for this was adapted from previous work [12] and our ICD10 code list was adapted from Statistics on Alcohol, England [16]. We also searched for evidence of viral hepatitis, autoimmune and metabolic diseases. Aetiology was ascribed in a hierarchical fashion of viral hepatitis, autoimmune or metabolic disease and alcoholic cirrhosis. If a patient had no recorded aetiology they were ascribed a cryptogenic aetiology. 


\section{Stage of disease}

We defined stages of disease as agreed at the Baveno IV consensus conference [17]. Each of the four stages is defined by the presence or absence of certain clinical symptoms. Stages 1 and 2 represent compensated cirrhosis and stages 3 and 4 decompensated cirrhosis.

\section{Statistical analysis}

We used death from any cause as the primary outcome in our study and excluded patients whose diagnosis date was concurrent with date of death. We tested for baseline differences between patient groups using chi-squared. Date of emergency hospital admission for liver disease was a time-varying variable, with follow-up split at this date to identify two groups based on time-at-risk:

(1) Patients in group 1 and group 2 (up to their emergency hospital admission date) contributed time-at-risk to the ambulatory group.

(2) Patients in group 2 (followed-up from their emergency hospital admission date onwards) and group 3 contributed time-at-risk to the subsequent to hospitalisation group.

We plotted a Kaplan-Meier survival curve to show the difference in survival by timeat-risk and estimated survival probabilities (and 95\% confidence intervals (CI)) overall and at 1- and 5-years. In order to determine how survival differed between the two time-at-risk groups we used Cox regression to estimate hazard ratios (HR) adjusting for potential confounders of age, sex, aetiology and stage of disease in our model. The proportional hazards assumption was checked using log-log plots. 
Clinically relevant interactions were tested with likelihood ratio tests. Stata version 12 MP4 was used for all statistical analyses and a P-value $<0.05$ was taken as the cutoff for statistical significance. 


\section{RESULTS}

\section{Incident cases}

A total of 5247 people aged 18 and over were identified as incident cirrhosis cases between January 1998 and December 2009, 2965 from primary care records and an additional 2282 from secondary care. 129 (2.5\%) patients whose date of diagnosis was concurrent with death were excluded, establishing an incident study cohort of 5118 people diagnosed with cirrhosis during the observation period.

\section{Validation of case definition}

A total of 2975 cases were identified in primary care, 10 were excluded as they had a cirrhosis-related hospitalisation before 1998, 2721 (91.5\%) were hospitalised during the observation period and 2230 (75\%) had a diagnosis or procedure related to liver disease. Out of the 2282 patients with a record of cirrhosis in secondary care over $90.4 \%(n=2062)$ had either death or additional evidence related to liver disease in their records, or a confirmation of a cirrhosis diagnosis in their free text.

\section{Patient groups}

2472 patients (48.3\% of the incident cohort) were ambulatory at first diagnosis. Of these, $1648(66.6 \%)$ remained ambulatory throughout the study period (group (1)) and $825(33.4 \%)$ had a subsequent emergency hospital admission for liver disease (group (2)). 2646 patients had a first diagnosis during an emergency admission (group (3), 51.7\%). 


\section{Patient characteristics}

The cohort of 5118 patients had a mean age of $59.3(\mathrm{sd}=14.3)$ years and slightly more men (57.9\%) than women; just over half of the population had an aetiology of alcoholic cirrhosis (53.9\%) (see Table 1). A higher proportion of men than women had alcoholic cirrhosis, $61.9 \%$ vs.42.8\% respectively $\left(\chi_{(3)}^{2}=235.7, P<0.001\right)$. Just over half of the study population $(55.9 \%)$ had compensated cirrhosis (Baveno IV stages 1 or 2 ) at diagnosis.

The distribution of age, sex, stage of disease and aetiology varied between the ambulatory and hospitalised at first diagnosis groups: the latter had a substantially lower proportion of people with alcoholic cirrhosis, almost twice the proportion of people with viral hepatitis $\left(\chi_{(3)}^{2}=162.8, P<0.001\right)$, and a smaller proportion of men $\left(\chi_{(1)}^{2}=4.9, P=0.03\right)$ compared to the former. The hospitalised at first diagnosis group had a higher proportion of younger patients than the ambulatory at first diagnosis group $\left(\chi_{(4)}^{2}=33.5, P<0.001\right)$. A lower proportion of the ambulatory at first diagnosis group had decompensated cirrhosis $\left(21.2 \%\right.$ vs. $\left.65.4 \%, \chi_{(3)}^{2}=1000, P<0.001\right)$ than the hospitalised

at first

diagnosis group. 


\section{Survival}

In a total of 14,743 person-years of follow-up (median length of follow-up 1.97 [IQR 0.42 to 4.39] years), there were 2565 (50.1\%) deaths in our cohort. Overall the survival probabilities were $0.70(95 \% \mathrm{Cl} 0.69-0.72)$ at 1 -year and $0.47(95 \% \mathrm{Cl} 0.45$ $0.49)$ at 5 -years. For the ambulatory group survival probabilities at 1 - and 5-years were $0.88(95 \% \mathrm{Cl} 0.87,0.90)$ and $0.74(95 \% \mathrm{Cl} 0.72,0.77)$ respectively and 0.56 $(95 \% \mathrm{Cl} 0.54,0.58)$ and $0.30(95 \% \mathrm{Cl} 0.29,0.32)$ respectively for the subsequent to hospitalisation group (see Figure 1). The Kaplan-Meier curve was truncated at 5 years given that there was little follow-up time there onwards.

Table 2 shows the survival probabilities at 5 -years stratified by sex, time-at-risk, aetiology and age. They have been presented this way to provide prognostic information that could be applied easily in a clinical setting. Supplementary Table 2 shows the equivalent 1-year survival probabilities. In general, survival decreased with age, was better for women and overall did not differ substantially between the different aetiologies, apart from a few instances. Supplementary Table 3 provides clinical examples that demonstrate how the survival estimates vary dependent on the clinical setting. 


\section{Multivariate analysis}

Adjusting for age, sex, aetiology and disease stage the risk of death was independently higher subsequent to hospitalisation compared to the ambulatory group ( $\mathrm{HR}=4.11,95 \% \mathrm{Cl} 3.70,4.58)$. The risk of death in those with decompensated cirrhosis was only 1.2 -fold that of patients with compensated cirrhosis $(95 \% \mathrm{Cl} 1.11$, 1.31) adjusting for confounders. The multivariate Cox regression model is shown in Table 3. There was a statistically significant interaction between aetiology and age in the Cox regression model $\left(\chi_{(12)}^{2}=26.4, P<0.001\right)$, adjusting for sex, stage of disease and time-at-risk group. Comparing the alcoholic with the cryptogenic patients there was approximately a two-fold risk of death in those younger than 45 years but no significant difference for patients older than 55 years. We report the adjusted hazard for each age-group by aetiology in Table 3 . 


\section{DISCUSSION}

\section{Main findings}

Our study is the first to use both primary and secondary healthcare linked data to establish a comprehensive cohort of people with incident cirrhosis in England and consequently to take into account the transition from ambulatory to hospitalised timeat-risk when calculating accurate survival estimates. Our findings show that patients who remain entirely ambulatory have a 5 -year survival of $74 \%$ which is comparable to that seen for cancer of the bladder [18]. In contrast, once a patient is hospitalised for an emergency their survival drops markedly. Indeed our findings suggest that emergency hospitalisation for liver disease heralds a downturn in a patient's outlook independent of their stage of cirrhosis. This we believe is important both for policy makers but also for clinical practice as we provide precise estimates of survival derived from an unbiased population that represents the generality of patients with cirrhosis. These estimates, stratified by age, sex and aetiology can help with health care service provision planning but equally they can be used to communicate prognosis to patients based on a clinical assessment of disease and the natural history it undergoes. In addition, using emergency hospitalisation as a risk factor is a pragmatic way of determining prognosis as it is objective and relatively easy to define. 


\section{Strengths and limitations}

The largest potential limitation with a study trying to determine incidence from routinely collected data is confidence in case definition. Compared to previous studies which have used broad ICD10 code lists including non cirrhotic codes of K70.9 (alcoholic liver disease) and K74.3 (primary biliary cirrhosis) [19], our definition of cirrhosis was much more restrictive. The linked data have confirmed our case definitions by providing supporting evidence of liver disease among the various healthcare records and death registry, analogous to a chart review. Our current finding that a large proportion of patients diagnosed within the GPRD had a hospital admission related to liver disease $(75 \%)$ emphasises the reliability of our case definition (given that we would not expect all cirrhotic patients to require a hospital admission). The finding falls in line with our previous external validation of primary care records where review of patients' paper records confirmed cirrhosis in the majority of patient records checked [12]. In two recent systematic reviews case validity for most chronic conditions was described as good using the GPRD [20, 21].

In those presenting with cirrhosis in secondary care only, we found $90 \%$ had additional evidence of liver disease or death related to liver disease, or a mention of cirrhosis in their primary care written record. Kramer et al.[22] recently found ICD9 codes for cirrhosis had a $90 \%$ positive predictive value and $87 \%$ negative predictive value. Unlike the GPRD, HES data cannot be validated against medical records directly due to the annoymisation process used. A recent government audit found 91\% median accuracy [23] and our findings confirm accurate coding in the HES. 
Overall we believe our case definition is as robust as previously reported in bespoke case studies of cirrhosis from secondary care. That our population was not drawn from an individual tertiary referral centre is on its own a strength of the present study as the population is more representative of the entire spectrum of disease and is drawn from a population which is representative of the whole population of England [11].

Our group and others $[24,25]$ have shown previously that survival differs by disease stage i.e. compensated or decompensated cirrhosis. The majority of patients classified as ambulatory were compensated at diagnosis $(78.8 \%)$ whereas those who were hospitalised at first diagnosis were more likely to be decompensated (65.4\%) as per the Baveno IV staging. Our stratification into ambulatory or hospitalised onwards time-at-risk groups therefore perhaps reflects, to some extent, the transition from a compensated to decompensated state of disease. By using the date of emergency hospital admission as a time-varying variable to define our timeat-risk we have been able to add to our previous work, showing how those who initially present as ambulatory patients can have varied survival dependent on subsequent hospitalisation. Our study also highlights that irrespective of whether the patient had compensated or decompensated cirrhosis at first diagnosis, the key risk factor is having an emergency hospitalisation for liver disease. We cannot tease out from the data available what the exact cause of the hospital admission is and therefore are not able to speculate as to whether it is the liver disease per se or an event which occurs in hospital, which is affecting this difference in survival.

Several studies have used the Model for End-stage Liver Disease (MELD) or ChildTurcotte-Pugh scores $[26,27]$ to prognosticate survival for patients with cirrhosis and 
determine whether transplantation is necessary. Although we have not reported these scores in our study, due to lack of laboratory data, the attraction of our method is its simplicity and independence of laboratory measurements in determining longterm prognostic information. For those whom we could determine a MELD score $(\mathrm{n}=1415,27.6 \%)$ Baveno IV stage of disease was shown to be highly correlated $(p<0.001)$. We therefore took the pragmatic approach of using Baveno IV stage of disease to adjust our mortality estimates for disease severity as information on this variable was available for the entirety of our study population.

We identified a record of alcohol use consistent with it being the underlying aetiology of disease in just over $50 \%$ of the patients. This is almost identical to that found previously in the UK and also in Scandinavia suggesting that if there is any underreporting it is likely to have been slight $[3,12,28]$.

Finally, although we have ascertained the date of diagnosis and excluded prevalent individuals, the exact onset of a chronic disease process such as cirrhosis can't be ascertained without a population based screening programme. As there is no screening for cirrhosis in the National Health Service in England it is generally only diagnosed clinically when people first present to a healthcare provider. Our study therefore is relevant to the pragmatic approach that is the reality in clinical practice. 


\section{Other literature}

Our mortality analysis can be compared in detail with two large hospital-based studies from England and Denmark. In 2005, Roberts et al. described the survival experience of 8192 people admitted to hospital with either chronic liver disease or cirrhosis in the Oxford region between 1968 and 1999. Our 1-year survival in the subsequent to hospitalisation group (56\%) was lower than theirs $(66.4 \%)$ and lower than that of the large Danish cohort study (65.5\%) [3]. This is likely to be because our subsequent to hospitalisation group consisted of solely emergency admissions whereas the other two studies combined in- and out-patients. The recent Danish study by Fialla et al.[2] separated in- and out-patients and reported 1-year survival for their out-patients as $76 \%$ which was lower than that of our ambulatory group $(88 \%)$, most likely due to the fact that their out-patient group excluded ambulatory patients, a limitation highlighted by the authors.

In comparison with our previous study [25], survival at 1-year in the ambulatory group was almost identical to those who had compensated cirrhosis according to their primary care records (87.3\%) while survival at 1-year in the subsequent to hospitalisation group was worse than the survival of those who had decompensated cirrhosis $(75 \%)$. This demonstrates how survival of severely ill patients is over estimated if only primary care records are used. 
Although some previous studies include patients with all aetiology types, their geographical bias might lead to non-representative populations in terms of aetiology. Our population-based approach has eliminated such bias, enabling our survival estimates to be applied to the full heterogeneity of the cirrhotic population.

Most previous studies have found that those who had alcoholic cirrhosis had a worse prognosis than those without $[8,9]$. We were also able to report how relative mortality between aetiology groups differs by age, information that has not previously been available. We showed aetiology affected prognosis in young patients but less so in older patients; comparing the alcoholic with the cryptogenic patients there was approximately a two-fold risk of death in those younger than 45 years but no significant difference for patients older than 55 years. 


\section{Conclusion}

In summary we have established a comprehensive, contemporary cohort, representing the whole spectrum of people with cirrhosis in terms of their mode of presentation and aetiology of disease. We have determined survival estimates for patients with different presentations of the disease and taken into account the transition from being ambulatory to becoming hospitalised. We have shown that an emergency hospitalisation predicts a poorer prognosis irrespective of disease stage, and conversely that patients have a relatively good outcome whilst ambulatory. This finding may influence the way doctors manage and monitor their patients in the future as, in the UK and elsewhere, when patients are diagnosed with cirrhosis a range of services are often implemented such as surveillance for hepatocellular carcinoma and oesophageal varices [29-31]. Some of these health care interventions may not be necessary or appropriate in certain patient groups, in particular those with a very poor prognosis. Our results provide physicians as well as those planning health services with precise and unbiased estimates of survival which should help to allow optimisation of the allocation of limited resources. This may also allow evaluation of effectiveness of potential interventions that aim to reduce emergency admission among people with cirrhosis. 
Acknowledgements: J.W. had the original idea for the study and all authors contributed to its interpretation. S.R. was responsible for data management and performed the data analysis. S.R. and J.W. initially drafted the paper. K.M.F., C.J.C., and G.P.A. revised the paper critically and all authors approved the final version. The funders of this study had no role in the design, analysis or interpretation of the data. S.R. is funded by the Fellowship awarded to J.W. Approval was given by the Independent Scientific and Ethical Committee of the GPRD for this study (09_065RA_3). 


\section{REFERENCES}

[1] D'Amico G, Morabito A, Pagliaro L, Marubini E. Survival and prognostic indicators in compensated and decompensated cirrhosis. Dig Dis Sci 1986; 31:468-75.

[2] Fialla AD, Schaffalitzky de Muckadell OB, Lassen AT. Incidence, etiology and mortality of cirrhosis: a population-based cohort study. Scand J Gastroenterol 2012; 47:702-709.

[3] Jepsen P, Vilstrup H, Andersen PK, Lash TL, Sorensen HT. Comorbidity and survival of Danish cirrhosis patients: a nationwide population-based cohort study. Hepatology 2008; 48:214-220.

[4] Trevsani F, Magini G, Santi V, Morselli-Labate AM, Cantarini MC, Di Nolfo MA, et al. Impact of etiology of cirrhosis on the survival of patients diagnosed with hepatocellular carcinoma during surveillance. Am J Gastroenterology 2007; 102:1022-1031.

[5] Das K, Das K, Datta S, Pal S, Hembram JR, Dhali GK et al. Course of disease and survival after onset of decompensation in hepatitis B virus-related. Liver International 2010; 30:1033-1042.

[6] De Jongh FE, Janssen HL, de Man RA, Hop WC, Schalm SW, van Blankenstein M. Survival \& prognostic indicators in hepatitis B surface antigen-positive cirrhosis of the liver. Gastroenterology 1992; 103:1630-1635.

[7] Hui AY, Chan HL, Leing NW, Hung LC, Chan FK, Sung JJ.Survival and prognostic indicators in patients with hepatitis B virus-related cirrhosis after onset of hepatic decompensation. J Clin Gastronenterol 2002; 34:569-572. 
[8] Fleming KM, Aithal GP, Card TR, West J. All-cause mortality in people with cirrhosis compared with the general population: a population-based cohort study. Liver Int 2011; 32:79-84.

[9] Roberts SE, Goldacre MJ, Yeates D. Trends in mortality after hospital admission for liver cirrhosis in an English population from 1968 to 1999. Gut 2005; 54:16151621.

[10] Alikhan R, Peters F, Wilmott R, Cohen AT. Fatal pulmonary embolism in hospitalised patients: a necropsy review. Clinical Pathology 2004; 57 (12): 12541257.

[11] Walley T, Mantgani A. The UK General Practice Reserach Database. Lancet 1997; 350:1097-1099.

[12] Fleming KM, Aithal GP, Solaymani-Dodaran M, Card TR, West J. Incidence and prevalence of cirrhosis in the United Kingdom, 1992-2001: A general populationbased study. J Hepatol 2008; 49:732-738.

[13] Lewis JD, Biker WB, Weinstein RB, Strom BL. The relationship between time since registration and measured incidence rates in the General Practice Research Database. Pharmacoepidemiol Drug Saf 2005; 14:443-451.

[14] NHS Information Centre [Intermet]. Available at http://www.ic.nhs.uk/ (last accessed $15^{\text {th }}$ February 2013).

Chief

Medical

Officer

[Internet]

http://www.dh.gov.uk/en/Publichealth/Alcoholmisuse/DH 125368 (last accessed $19^{\text {th }}$ December 2012).

[16] Information Centre [Internet]. Available at http://www.ic.nhs.uk/pubs/alcohol12/ (last accessed $15^{\text {th }}$ February 2013). 
[17] De Franchis R. Evolving consensus in portal hypertension,. Report of the Baveno IV consensus workshop on methodology of diagnosis and therapy in potal hypertension. J Heptol 2005; 43(1):167-76.

Cancer

research

UK

[Internet].

Available

at

http://info.cancerresearchuk.org/cancerstats/(last accessed $15^{\text {th }}$ February 2013).

[19] Leon DA, McCambridge J. Liver cirrhosis mortality rates in Britain from 1950 to 2002: an analysis of routine data. Lancet 2006; 367(9504):52-56.

[20] Khan NF, Harrison SE, Rose PW. Validity of diagnostic coding within the General Practice Research Database: a systematic review. British Journal of General Practice 2010; 60:e128-e136(9).

[21] Herrett E, Thomas SL, Schoonen WM, Smeeth L, Hall AJ. Validation and validity of diagnoses in the General Practice Research Database: a systematic review. Br J Clin Pharmacol 2010. 69(1): 4-14.

[22] Kramer JR, Davila JA, Miller ED, Richardson P, Giordano TP, El-Seraq HB. The validity of viral hepatitis and chronic liver disease diagnoses in Veterans Affairs administrative databases. Aliment Pharmacol \& Ther 2008; 27:274-282.

[23] Audit Commission. Improving data quality in the NHS Annual report on the PbR assurance programme. Audit Commission Publishing Team 2010.

[24] Fleming KM, Aithal GP, Card TR West J. The rate of decompensation and clinical progression of disease in people with cirrhosis: a cohort study. Aliment Pharmacol Ther 2010; 32:1343-1350. 
[25] Jepsen P, Ott P, Andersen PK, Sorensen HT, Vilstrup H. Clinical course of alcoholic liver cirrhosis: A Danish population-based cohort study. Hepatology 2010; $51: 675-682$.

[26] Kamath PS, Wiesner RH, Malnichoc M, Kremers W, Therneau TM, Kosberg CL et al. A model to predict survival in patients with end-stage liver disease. Hepatology $2001 ; 33: 464-470$.

[27] Christensen E, Schilting P, Fauerholdt L, Gluud C, Andersen PK, Juhl E et al. Prognostic value of Child-Turcotte criteria in medically treated cirrhosis. American assoc for the study of liver diseases $1984 ; 4: 430-435$.

[28] Saunders JB, Walters JR, Davies AP, Paton A. A 20-year prospective study of cirrhosis. Br Med J (Clin Res Ed) 1981; 282:263-266.

[29] Guidelines for HCC surveillance [internet] Available at http://www.bsg.org.uk/clinical-guidelines/liver/guidelines-for-the-diagnosis-and-treatment-ofhepatocellular-carcinoma-hcc-in-adults.html (last accessed $9^{\text {th }}$ May 2013). [30] Jalan R, Hayes P. UK guidelines on the management of variceal haemorrhage in cirrhotic patients. GUT 2000; 46(3): iii1-iii15.

[31] El-Serag HB, Davila JA. Surveillance for hepatocellular carcinoma: in whom and how? Therap Adv Gastroenterol 2011; 4(1): 5-10. 
Table 1 Patient characteristics of the incident study cohort, 1998-2009

\begin{tabular}{|c|c|c|c|c|c|c|}
\hline & Males & & & Females & & \\
\hline Patient group & $\begin{array}{l}\text { Ambulatory } \\
\text { at first } \\
\text { diagnosis } \\
n=1393\end{array}$ & $\begin{array}{l}\text { Hospitalised } \\
\text { at first } \\
\text { diagnosis } \\
n=1572\end{array}$ & $\begin{array}{l}\text { Overall } \\
n=2965\end{array}$ & $\begin{array}{l}\text { Ambulatory } \\
\text { at first } \\
\text { diagnosis } \\
n=1079\end{array}$ & $\begin{array}{l}\text { Hospitalised } \\
\text { at first } \\
\text { diagnosis } \\
n=1074\end{array}$ & $\begin{array}{l}\text { Overall } \\
n=2153\end{array}$ \\
\hline $\begin{array}{l}\text { Median f/up [IQR] } \\
\text { Yrs* }^{*}\end{array}$ & $\begin{array}{l}1.66 \\
{[0.42,3.82]}\end{array}$ & $\begin{array}{l}1.15 \\
{[0.14,3.36]}\end{array}$ & $\begin{array}{l}1.75 \\
{[0.37,4.11]}\end{array}$ & $\begin{array}{l}2.35 \\
{[0.85,4.77]}\end{array}$ & $\begin{array}{l}1.37 \\
{[0.13,3.69]}\end{array}$ & $\begin{array}{l}2.25 \\
{[0.55,4.82]}\end{array}$ \\
\hline No. deaths (\%) & $617(44.3)$ & $939(59.7)$ & $1556(52.5)$ & $375(34.5)$ & $634(59)$ & $1009(46.9)$ \\
\hline $\begin{array}{l}\text { No. with aetiology } \\
\text { (\%) } \\
\text { Alcohol }\end{array}$ & $758(54.4)$ & $1076(68.4)$ & $1834(61.9)$ & $355(32.9)$ & $567(52.8)$ & $922(42.8)$ \\
\hline Viral hepatitis & $203(14.6)$ & $132(8.4)$ & $335(11.3)$ & $146(13.5)$ & $93(8.7)$ & $239(11.1)$ \\
\hline $\begin{array}{l}\text { Autoimmune/ } \\
\text { Metabolic disease }\end{array}$ & $105(7.5)$ & $78(5)$ & $183(6.2)$ & $210(19.5)$ & $112(10.4)$ & $322(15)$ \\
\hline Cryptogenic & $327(23.5)$ & $286(18.2)$ & $613(20.7)$ & $368(34.1)$ & $302(28.1)$ & $670(31.1)$ \\
\hline Mean age (sd) yrs & $59.2(13)$ & $57.9(14.5)$ & $58.5(13.8)$ & $61.3(14.7)$ & $59.4(14.9)$ & $60.3(14.8)$ \\
\hline $\begin{array}{l}\text { Age at diagnosis } \\
\text { (\%) yrs: } \\
<45\end{array}$ & $170(12.2)$ & $276(17.6)$ & $446(15)$ & $137(12.7)$ & $167(15.6)$ & $304(14.1)$ \\
\hline 45 to 54 & $318(22.8)$ & $384(24.4)$ & $702(23.7)$ & $203(18.8)$ & $244(22.7)$ & $447(20.8)$ \\
\hline 55 to 64 & 417 (29.9) & $373(23.7)$ & $790(26.6)$ & $254(23.5)$ & $258(24)$ & $512(23.8)$ \\
\hline 65 to 74 & $292(21)$ & $288(18.3)$ & $580(19.6)$ & $245(22.7)$ & $195(18.2)$ & $440(20.4)$ \\
\hline $75+$ & $196(14.1)$ & $251(16)$ & $447(15.1)$ & $240(22.2)$ & $210(19.6)$ & $450(20.9)$ \\
\hline $\begin{array}{l}\text { Baveno IV stage } \\
1\end{array}$ & $819(27.6)$ & $388(24.7)$ & $1207(40.7)$ & $652(30.3)$ & $286(26.6)$ & $938(43.6)$ \\
\hline 2 & $269(9.1)$ & $163(10.4)$ & $432(14.6)$ & $207(9.6)$ & $78(7.3)$ & $285(13.2)$ \\
\hline 3 & $178(6)$ & $649(41.3)$ & 827 (27.9) & $149(6.9)$ & $472(44)$ & $621(28.8)$ \\
\hline 4 & $127(4.3)$ & $372(23.7)$ & $499(16.8)$ & 71 (3.3) & 238 (22.2) & $309(14.4)$ \\
\hline
\end{tabular}

* Follow-up for the Ambulatory at first diagnosis is from time of diagnosis to end of follow-up or emergency hospitalisation (for those who had one). 
Table 2 Survival probabilities $(95 \% \mathrm{Cl})$ at 5 -years by sex, time-at-risk, aetiology and age

\begin{tabular}{|c|c|c|c|c|}
\hline \multirow[b]{2}{*}{ Aetiology } & \multicolumn{2}{|l|}{ Males } & \multicolumn{2}{|l|}{ Females } \\
\hline & $\begin{array}{l}\text { Ambulatory } \\
n=1393\end{array}$ & $\begin{array}{l}\text { Subsequent to } \\
\text { hospitalisation } \\
\mathrm{n}=2067\end{array}$ & $\begin{array}{l}\text { Ambulatory } \\
\mathrm{n}=1079\end{array}$ & $\begin{array}{l}\text { Subsequent to } \\
\text { hospitalisation } \\
n=1404\end{array}$ \\
\hline \multicolumn{5}{|l|}{ Alcoholic $n=2756$} \\
\hline$<45 \mathrm{yrs}$ & $0.79(0.63,0.89)$ & $0.47(0.39,0.54)$ & $0.87(0.69,0.95)$ & $0.50(0.39,0.60)$ \\
\hline 45 to 54 & $0.78(0.68,0.85)$ & $0.39(0.33,0.45)$ & $0.82(0.70,0.89)$ & $0.35(0.28,0.43)$ \\
\hline 55 to 64 & $0.70(0.61,0.77)$ & $0.30(0.25,0.36)$ & $0.79(0.64,0.89)$ & $0.38(0.31,0.45)$ \\
\hline 65 to 74 & $0.71(0.60,0.79)$ & $0.21(0.15,0.27)$ & $0.88(0.73,0.95)$ & $0.21(0.13,0.31)$ \\
\hline $75+$ & $0.37(0.19,0.54)$ & $0.07(0.03,0.13)$ & $0.50(0.24,0.72)$ & $0.16(0.06,0.29)$ \\
\hline Overall & $0.70(0.65,0.74)$ & $0.31(0.28,0.34)$ & $0.79(0.73,0.85)$ & $0.35(0.31,0.39)$ \\
\hline \multicolumn{5}{|l|}{ Viral hepatitis $n=574$} \\
\hline$<45 \mathrm{yrs}$ & $0.77(0.59,0.88)$ & $0.39(0.23,0.55)$ & $0.92(0.54,0.99)$ & $0.54(0.31,0.72)$ \\
\hline 45 to 54 & $0.92(0.79,0.97)$ & $0.31(0.19,0.44)$ & $0.87(0.63,0.96)$ & $0.47(0.27,0.64)$ \\
\hline 55 to 64 & $0.81(0.62,0.91)$ & $0.44(0.26,0.61)$ & $0.92(0.57,0.99)$ & $0.34(0.16,0.53)$ \\
\hline 65 to 74 & $0.65(0.18,0.90)$ & 0 & $0.84(0.61,0.94)$ & $0.25(0.07,0.49)$ \\
\hline $75+$ & $0.47(0.15,0.74)$ & $0.06(0.03,0.25)$ & $0.61(0.36,0.79)$ & $0.10(0.02,0.28)$ \\
\hline Overall & $0.79(0.70,0.86)$ & $0.31(0.23,0.38)$ & $0.83(0.73,0.90)$ & $0.36(0.27,0.46)$ \\
\hline \multicolumn{5}{|l|}{$\begin{array}{l}\text { Autoimmune/Metabolic } \\
\text { disease } n=505\end{array}$} \\
\hline$<45 \mathrm{yrs}$ & $0.83(0.27,0.97)$ & $0.47(0.15,0.74)$ & 1 & $0.91(0.51,0.99)$ \\
\hline 45 to 54 & 1 & $0.32(0.12,0.54)$ & 1 & $0.45(0.24,0.65)$ \\
\hline 55 to 64 & $0.88(0.57,0.97)$ & $0.25(0.12,0.41)$ & $0.98(0.84,0.99)$ & $0.57(0.35,0.74)$ \\
\hline 65 to 74 & $0.82(0.52,0.94)$ & $0.36(0.17,0.56)$ & $0.86(0.71,0.94)$ & $0.17(0.08,0.28)$ \\
\hline $75+$ & $0.65(0.34,0.84)$ & 0 & $0.72(0.48,0.87)$ & 0 \\
\hline Overall & $0.84(0.72,0.88)$ & $0.28(0.19,0.37)$ & $0.90(0.83,0.94)$ & $0.28(0.20,0.36)$ \\
\hline \multicolumn{5}{|l|}{ Cryptogenic $n=1283$} \\
\hline$<45 \mathrm{yrs}$ & $0.81(0.44,0.94)$ & $0.72(0.48,0.87)$ & $0.93(0.79,0.98)$ & $0.79(0.62,0.89)$ \\
\hline 45 to 54 & $0.95(0.81,0.99)$ & $0.49(0.27,0.68)$ & $0.98(0.84,0.99)$ & $0.42(0.18,0.65)$ \\
\hline 55 to 64 & $0.74(0.59,0.84)$ & $0.12(0.04,0.23)$ & $0.85(0.70,0.93)$ & $0.47(0.30,0.62)$ \\
\hline 65 to 74 & $0.47(0.33,0.60)$ & $0.18(0.09,0.30)$ & $0.62(0.48,0.74)$ & $0.26(0.16,0.37)$ \\
\hline $75+$ & $0.41(0.25,0.55)$ & $0.10(0.06,0.16)$ & $0.58(0.48,0.68)$ & $0.12(0.07,0.19)$ \\
\hline Overall & $0.61(0.53,0.68)$ & $0.19(0.14,0.24)$ & $0.72(0.67,0.78)$ & $0.29(0.24,0.35)$ \\
\hline Total & $0.70(0.66,0.73)$ & $0.29(0.26,0.31)$ & $0.79(0.76,0.82)$ & $0.33(0.30,0.36)$ \\
\hline
\end{tabular}

$\mathrm{Cl}=$ confidence intervals 
Table 3: Multivariate cox regression model for $n=5118$ patients

\begin{tabular}{|c|c|c|}
\hline & Adjusted hazard ratios $(95 \% \mathrm{Cl})^{*}$ & P-value \\
\hline $\begin{array}{l}\text { Time at risk: } \\
\text { Ambulatory } \\
\text { Hospitalised }\end{array}$ & $\begin{array}{l}\text { Ref } \\
4.11(3.7,4.58)\end{array}$ & $<0.001$ \\
\hline $\begin{array}{l}\text { Gender: } \\
\text { Male } \\
\text { Female }\end{array}$ & $\begin{array}{l}\text { Ref } \\
0.83(0.76,0.90)\end{array}$ & $<0.001$ \\
\hline $\begin{array}{l}\text { Age at diagnosis (\%) yrs: } \\
<45 \\
45 \text { to } 54 \\
55 \text { to } 64 \\
65 \text { to } 74 \\
75+\end{array}$ & $\begin{array}{l}\text { Ref } \\
1.78(1.03,3.09) \\
3.34(2.09,5.35) \\
4.53(2.91,7.05) \\
6.94(4.51,10.7)\end{array}$ & $<0.001$ \\
\hline $\begin{array}{l}\text { Aetiology (\%): } \\
\text { Cryptogenic } \\
\text { Alcohol } \\
\text { Viral hepatitis } \\
\text { Autoimmune/ } \\
\text { Metabolic disease }\end{array}$ & $\begin{array}{l}\text { Ref } \\
1.82(1.17,2.84) \\
2.03(1.23,3.37) \\
0.81(0.36,1.82)\end{array}$ & 0.01 \\
\hline $\begin{array}{l}\text { Interaction age and aetiology } \\
<45 \text { years } \\
\text { Cryptogenic } \\
\text { Alcohol } \\
\text { Viral hepatitis } \\
\text { Autoimmune/ } \\
\text { Metabolic disease } \\
\text { 45-54 years } \\
\text { Cryptogenic } \\
\text { Alcohol } \\
\text { Viral hepatitis } \\
\text { Autoimmune/ } \\
\text { Metabolic disease } \\
55-64 \text { years } \\
\text { Cryptogenic } \\
\text { Alcohol }\end{array}$ & $\begin{array}{l}\text { Ref } \\
1.81(1.17,2.84) \\
2.03(1.23,3.37) \\
0.81(0.55,2.21) \\
\text { Ref } \\
1.46(1.00,2.11) \\
1.36(0.87,2.06) \\
1.28(0.77,2.14) \\
\text { Ref } \\
0.90(0.72,1.14)\end{array}$ & $<0.001$ \\
\hline
\end{tabular}

$30 \mid \mathrm{P}$ a g e 


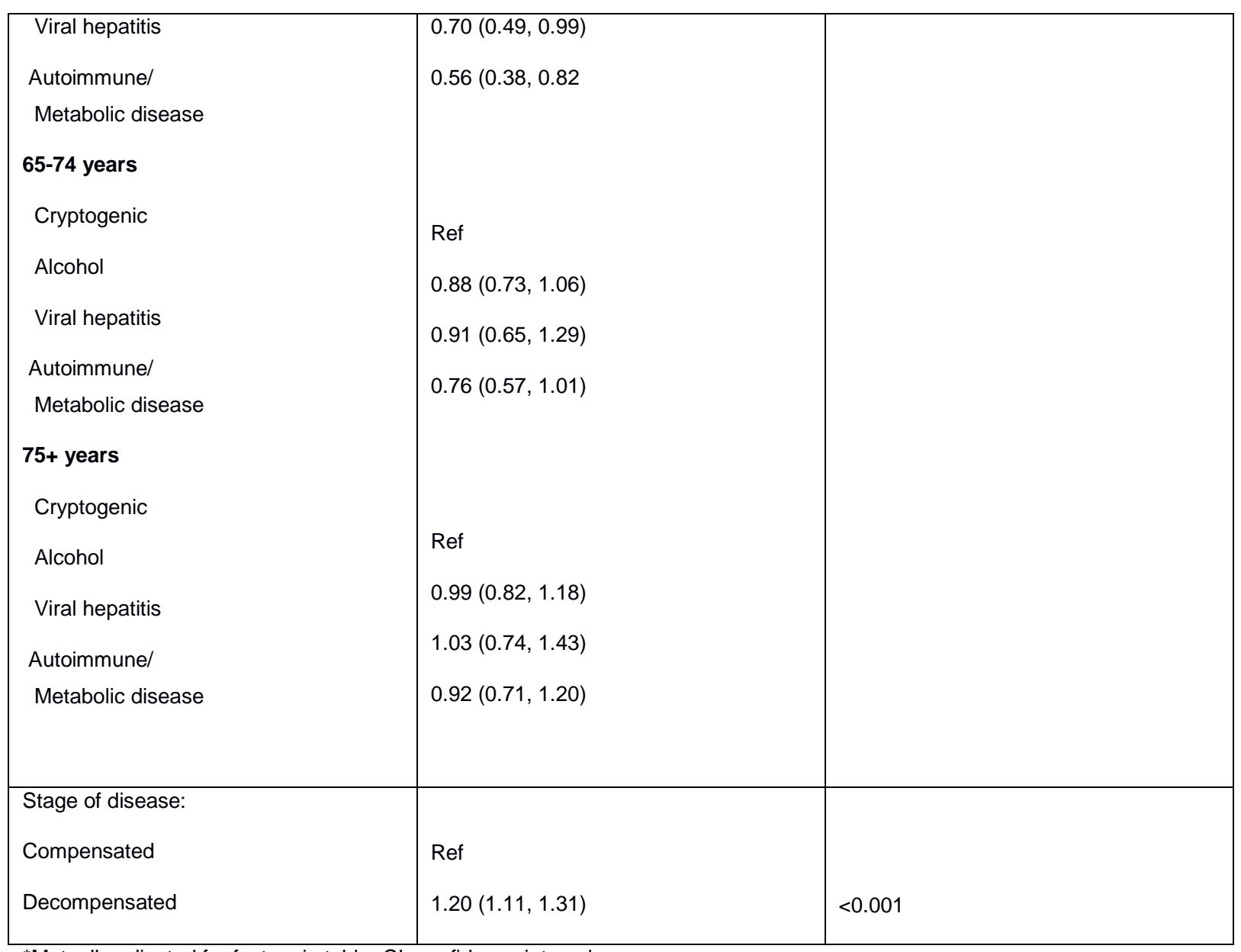

${ }^{*}$ Mutually adjusted for factors in table. $\mathrm{Cl}=$ confidence intervals 


\section{Figure legends}

Fig. 1 Survival estimates within 5 years by time-at-risk group

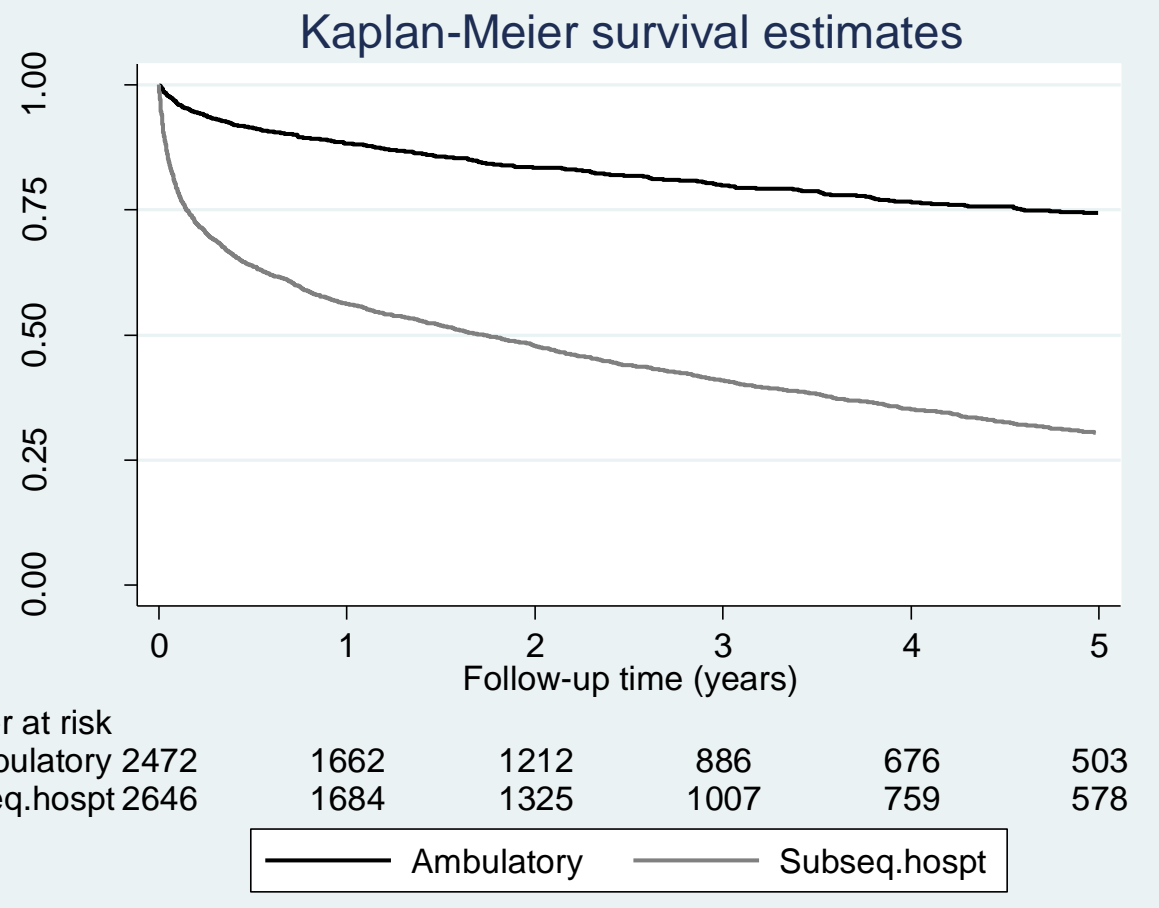

Number at risk is calculated at each point by excluding previous deaths and censored events 


\section{Supplementary Tables}

Table 1: Patient characteristics for Group2: 'Ambulatory with subsequent emergency admission for liver disease'

\begin{tabular}{|c|c|c|}
\hline & $\begin{array}{l}\text { Males } \\
\mathrm{n}=495\end{array}$ & $\begin{array}{l}\text { Females } \\
\mathrm{n}=\mathbf{3 3 0}\end{array}$ \\
\hline Median f/up [IQR] & 1.04 & 1.22 \\
\hline Yrs $^{*}$ & {$[0.15,2.92]$} & {$[0.20,3.16]$} \\
\hline No. deaths (\%) & $318(64.2)$ & $198(60)$ \\
\hline No. with aetiology (\%) & & \\
\hline Alcohol & $301(60.8)$ & $156(47.3)$ \\
\hline Viral hepatitis & $80(16.2)$ & $52(15.8)$ \\
\hline Autoimmune/ & & \\
\hline Metabolic disease & $42(8.5)$ & $67(20.3)$ \\
\hline Cryptogenic & $72(14.5)$ & $55(16.7)$ \\
\hline Mean age (sd) yrs & $59.1(12.2)$ & $60.7(14.3)$ \\
\hline $\begin{array}{l}\text { Age at diagnosis (\%) yrs: } \\
<45\end{array}$ & $50(10.1)$ & $42(12.7)$ \\
\hline 45 to 54 & $124(25.1)$ & $66(20)$ \\
\hline 55 to 64 & $160(32.3)$ & $71(21.5)$ \\
\hline 65 to 74 & $100(20.2)$ & $90(27.3)$ \\
\hline $75+$ & $61(12.3)$ & $61(18.5)$ \\
\hline \multicolumn{3}{|l|}{ Baveno IV stage } \\
\hline 1 & $273(55.2)$ & $204(61.8)$ \\
\hline 2 & $87(17.6)$ & $44(13.3)$ \\
\hline 3 & $82(16.6)$ & $58(17.6)$ \\
\hline 4 & $53(10.7)$ & $24(7.3)$ \\
\hline
\end{tabular}

* Follow-up from date of emergency hospitalisation to end of follow-up 
Table 2 Survival probabilities $(95 \% \mathrm{Cl})$ at 1-year by sex, time-at-risk, aetiology and age-group

\begin{tabular}{|c|c|c|c|c|}
\hline \multirow[b]{2}{*}{ Aetiology } & \multicolumn{2}{|l|}{ Males } & \multicolumn{2}{|l|}{ Females } \\
\hline & $\begin{array}{l}\text { Ambulatory* } \\
n=1393\end{array}$ & $\begin{array}{l}\text { Subsequent to } \\
\text { hospitalisation } ¥ \\
\mathrm{n}=2067\end{array}$ & $\begin{array}{l}\text { Ambulatory } \\
n=1079\end{array}$ & $\begin{array}{l}\text { Subsequent to } \\
\text { hospitalisation } \\
n=1404\end{array}$ \\
\hline \multicolumn{5}{|l|}{$\begin{array}{l}\text { Alcoholic } \\
n=2756\end{array}$} \\
\hline$<45 \mathrm{yrs}$ & $0.89(0.79,0.95)$ & $0.75(0.69,0.81)$ & $0.91(0.78,0.97)$ & $0.76(0.67,0.83)$ \\
\hline 45 to 54 & $0.89(0.83,0.93)$ & $0.64(0.58,0.69)$ & $0.94(0.87,0.97)$ & $0.66(0.59,0.73)$ \\
\hline 55 to 64 & $0.85(0.79,0.89)$ & $0.61(0.56,0.66)$ & $0.92(0.84,0.96)$ & $0.59(0.51,0.65)$ \\
\hline 65 to 74 & $0.86(0.79,0.91)$ & $0.47(0.40,0.53)$ & $0.96(0.86,0.99)$ & $0.53(0.42,0.62)$ \\
\hline $75+$ & $0.65(0.52,0.75)$ & $0.31(0.22,0.40)$ & $0.86(0.66,0.94)$ & $0.30(0.17,0.45)$ \\
\hline Overall & $0.85(0.82,0.87)$ & $0.59(0.56,0.62)$ & $0.92(0.89,0.95)$ & $0.62(0.58,0.65)$ \\
\hline \multicolumn{5}{|c|}{$\begin{array}{l}\text { Viral hepatitis } \\
n=574\end{array}$} \\
\hline$<45$ yrs & $0.95(0.83,0.99)$ & $0.69(0.53,0.81)$ & 1.0 & $0.72(0.49,0.87)$ \\
\hline 45 to 54 & $0.97(0.88,0.99)$ & $0.56(0.42,0.68)$ & $0.93(0.74,0.98)$ & $0.77(0.57,0.88)$ \\
\hline 55 to 64 & $0.98(0.85,0.99)$ & $0.68(0.48,0.82)$ & 1.0 & $0.63(0.39,0.79)$ \\
\hline 65 to 74 & $0.94(0.67,0.99)$ & $0.33(0.13,0.55)$ & $0.97(0.80,1.0)$ & $0.78(0.46,0.92)$ \\
\hline $75+$ & $0.81(0.42,0.95)$ & $0.17(0.03,0.42)$ & $0.73(0.50,0.87)$ & $0.33(0.11,0.57)$ \\
\hline Overall & $0.96(0.91,0.98)$ & $0.57(0.48,0.64)$ & $0.93(0.87,0.97)$ & $0.67(0.57,0.75)$ \\
\hline \multicolumn{5}{|c|}{$\begin{array}{l}\text { Autoimmune/Metabolic } \\
n=505\end{array}$} \\
\hline$<45 \mathrm{yrs}$ & 1.0 & $0.92(0.54,0.99)$ & 1.0 & $0.91(0.51,0.99)$ \\
\hline 45 to 54 & 1.0 & $0.53(0.27,0.74)$ & 1.0 & $0.70(0.45,0.85)$ \\
\hline 55 to 64 & $0.96(0.75,0.99)$ & $0.54(0.27,0.74)$ & 1.0 & $0.75(0.52,0.88)$ \\
\hline 65 to 74 & 1.0 & $0.60(0.36,0.78)$ & $0.98(0.89,1.00)$ & $0.54(0.35,0.69)$ \\
\hline $75+$ & $0.81(0.52,0.94)$ & $0.23(0.06,0.47)$ & $0.86(0.71,0.93)$ & $0.38(0.22,0.55)$ \\
\hline Overall & $0.96(0.89,0.98)$ & $0.56(0.45,0.66)$ & $0.96(0.89,0.98)$ & $0.60(0.50,0.68)$ \\
\hline \multicolumn{5}{|c|}{$\begin{array}{l}\text { Cryptogenic } \\
n=1283\end{array}$} \\
\hline$<45 \mathrm{yrs}$ & $0.92(0.72,0.98)$ & $0.79(0.56,0.90)$ & $0.93(0.79,0.98)$ & $0.82(0.65,0.91)$ \\
\hline 45 to 54 & $0.95(0.81,0.99)$ & $0.69(0.45,0.84)$ & $0.98(0.84,2.00)$ & $0.63(0.39,0.79)$ \\
\hline 55 to 64 & $0.85(0.74,0.92)$ & $0.28(0.15,0.42)$ & $0.94(0.84,0.98)$ & $0.57(0.41,0.69)$ \\
\hline 65 to 74 & $0.74(0.64,0.82)$ & $0.51(0.39,0.61)$ & $0.84(0.73,0.91)$ & $0.47(0.36,0.58)$ \\
\hline $75+$ & $0.74(0.60,0.82)$ & $0.28(0.21,0.35)$ & $0.76(0.68,0.83)$ & $0.31(0.24,0.39)$ \\
\hline Overall & $0.81(0.76,0.85)$ & $0.40(0.35,0.45)$ & $0.85(0.81,0.89)$ & $0.47(0.41,0.52)$ \\
\hline Total & $0.86(0.84,0.88)$ & $0.55(0.53,0.58)$ & $0.91(0.89,0.92)$ & $0.58(0.55,0.61)$ \\
\hline
\end{tabular}

$\mathrm{Cl}=$ confidence intervals. 
Table 3 Clinical examples of how survival estimates can be applied to different clinical settings

\begin{tabular}{|c|c|c|}
\hline Clinical example 1 & Clinical example 2 & Clinical example 3 \\
\hline $\begin{array}{l}\text { A 54-year old man, who only has minimal alcohol } \\
\text { intake, is taken to A\&E with haematemesis from } \\
\text { oesophageal varices and diagnosed with cirrhosis of a } \\
\text { non-alcoholic aetiology i.e. viral hepatitis. His } 1 \text { - and } 5 \text { - } \\
\text { year chances of survival are approximately } 56 \% \text { and } \\
31 \% \text { respectively. A woman with a similar patient } \\
\text { profile would have } 1 \text { - and } 5 \text {-year chances of survival of } \\
77 \% \text { and } 47 \% \text { respectively. }\end{array}$ & $\begin{array}{l}\text { A } 28 \text {-year old woman, who is a chronic alcohol drinker, } \\
\text { has a palpable liver and jaundice and is referred by her } \\
\text { GP to a hepatology clinic where she is diagnosed with } \\
\text { cirrhosis. One year later she is taken to A\&E with } \\
\text { oesophageal bleeding. Her } 1 \text { - and } 5 \text {-year chances of } \\
\text { survival are } 76 \% \text { and } 50 \% \text { respectively. By contrast a } \\
\text { similarly aged woman who has cryptogenic cirrhosis } \\
\text { and who is then admitted to hospital for her liver } \\
\text { disease has a chance of survival of } 82 \% \text { at } 1 \text {-year and } \\
79 \% \text { at } 5 \text {-years following hospitalisation. }\end{array}$ & $\begin{array}{l}\text { A } 44-y e a r \text { old woman, who has a history of alcohol } \\
\text { abuse has abnormal LFTs and is referred by her GP to } \\
\text { a hepatology clinic where she is diagnosed with } \\
\text { cirrhosis. Her } 1 \text { - and } 5 \text {-year chances of survival are } \\
91 \% \text { and } 87 \% \text { respectively. A few months later she is } \\
\text { admitted to hospital with haematemesis from } \\
\text { oesophageal varices. Following this hospital admission } \\
\text { her } 1 \text { - and } 5 \text {-year chances of survival, are reduced to } \\
76 \% \text { and } 50 \% \text { respectively. }\end{array}$ \\
\hline
\end{tabular}

35 P a g e 